\title{
The Effect of Single Leg and Double Leg Bounding Exercise Program (BEP) on Increasing the Physical Ability of Agility, Strength, Balance and Leg Muscle Power
}

\author{
Mohammad Zaim Zen ${ }^{1}$, Hari Setiono ${ }^{2}$, Nining Widyah ${ }^{3}$ \\ 1,2,3Universitas Negeri Surabaya, Indonesia
}

\begin{abstract}
:
The objectives of this study are to study and test the effect of using the effect of the single leg and double leg bounding exercise program (BEP) on the improvement of physical agility, strength, balance, and leg muscle power. The subjects of this study were 42 students of Physical Education class 2017 STKIP PGRI Jombang. This type of research is quantitative with quasiexperimental techniques. Sampling using the Solvin formula and purposive sampling technique. The process of taking data from the initial test and the final test uses the leg dynamometer test to determine leg muscle strength, side step test for agility, force plate test for leg muscle power, and balance beam test for balance. The results of the study on the normality and homogeneous tests showed normal and homogeneous data results with a significance value above 0.05. The mean difference test was carried out using the paired test and the Manova test. The method of increasing the agility, strength, balance and leg muscle power has a significant improvement with the two experimental methods. The conclusion of this study is that the bounding exercise program can significantly increase the agility, strength, balance and leg muscle power. However, from the two exercises the increase was greater in the group using the single leg bounding type of exercise.
\end{abstract}

Keywords: bounding; plyometrick; single leg; doubleg leg

\section{Introduction}

In the era of the modern world, fitness or physical condition experts try to take advantage of new scientific methods to prepare professional athletes in various national and international competitions. Therefore, the proper use of the best training methods is the most important basis that must be carried out by experienced professionals in the professional field. Currently, there is a wide variety of scientific research on athletes, competitions and physical training. In this case, one of the most effective ways in relation to increasing strength and increasing muscle endurance, speed and power of athletes is plyometric training (Aghababaei, 2010).

Bounding exercise program (BEP) is another potentially effective training program that can be carried out after a warm-up. It consists of a series of leg jump exercises characterized by a cycle of stretching-muscle shortening or an eccentric mobile phase, an amortization phase, and a concentric shortening phase. This stretch shortening cycle is to strengthen the elastic properties of muscle tissue connectives, thereby increasing muscle strength (during eccentric and concentric contractions) by allowing muscles to accumulate during the pre-stretch/eccentric phase and energy release or concentric phase ( $\mathrm{S}$. Van de Hoef, 2017). 
Bounding exercise program(BEP) is an exercise that prioritizes jumping, in the literature the Bounding exercise program (BEP) is referred to as a bound exercise this is because the exercise is a unit of a series of jumps, the Bounding exercise program (BEP) can also be categorized as a plyometric exercise. This plyometric exercise contains three phases, namely the eccentric phase, the amortization phase (the time between the eccentric and concentric contractions), and the concentric shortening phase (Davies G, 2015).

\subsection{Statement of the problems}

Based on the results of the explanation on the background of the problem, the formulation of the problem in this study is to identify Bounding Exercise Program exercises to increase physical agility, strength, and balance and leg muscle power.

\subsection{Purpose of the study}

This research has several objectives, including:

a. To analyze the effect of the Single leg bounding Exercise Program on increasing physical agility, strength, balance and leg muscle power in male students of the 2017 Physical Education Study Program STKIP PGRI Jombang.

b. To analyze the effect of the Double leg bounding Exercise Program on increasing physical agility, strength, balance and leg muscle power in male students of the 2017 Physical Education Study Program STKIP PGRI Jombang.

c. This study aims to analyze the difference in the effect of the single leg Bounding Exercise Program and the double leg Bounding Exercise Program on increasing physical agility, strength, balance and leg muscle power in male students of Physical Education Study Program class of 2017 STKIP PGRI Jombang.

\subsection{Research Question}

a. Is there a significant effect of the Single leg bounding Exercise Program on increasing physical agility, strength, and balance and leg muscle power in male students of the 2017 Physical Education Study Program STKIP PGRI Jombang?

b. Is there a significant effect of the Double leg bounding Exercise Program on increasing physical agility, strength, and balance and leg muscle power in male students of the 2017 STKIP PGRI Jombang Physical Education Study Program?

c. Is there a significant difference between the single leg Bounding Exercise Program and the double leg Bounding Exercise Program on increasing physical agility, strength, balance and leg muscle power in male students of Physical Education Study Program class of 2017 STKIP PGRI Jombang?

\subsection{Hypotheses}

The following null hypotheses were formulated and tested at 0.05 level of significance.

$\mathbf{H}_{\mathbf{1}} \mathbf{1}$ : There is a significant effect of the Single leg bounding Exercise Program on increasing physical agility, strength, and balance and leg muscle power in male students of the 2017 Physical Education Study Program STKIP PGRI Jombang.

$\mathbf{H}_{\mathbf{1}} \mathbf{2}$ : There is a significant effect of the Double leg bounding Exercise Program on increasing physical agility, strength, and balance and leg muscle power in male students of the 2017 Physical Education Study Program STKIP PGRI Jombang.

$\mathbf{H}_{1}$ 3: There is a significant difference between the effect of Single leg bounding Exercise Program and Double leg bounding Exercise Program on increasing physical agility, strength, and balance and leg muscle power in male students of Physical Education Study Program class of 2017 STKIP PGRI Jombang. 


\section{Review of Literature}

\subsection{Bounding Exercise Program}

Bounding Exercise Program is an exercise that has elements of the plyometric training method, namely SSC (short circle cycle). In addition, the Bounding Exercise Program (BEP) is carried out in a series. Plyometric training is a very popular form of physical conditioning of healthy individuals that has been studied extensively over the past decades (Slimani, 2016). The Bounding Exercise Program consists of a single leg jump exercise characterized by a stretch-shortening cycle: an eccentric pre-stretch phase, an amortization phase, and a concentric shortening phase (Davies, 2015). This fast stretching-shortening cycle will strengthen the elastic properties of muscle connective tissue, thereby increasing muscle performance (Chamari, 2004). Bounding Exercise Program exercises that require muscle contraction are carried out in a tied or continuous manner so that there is a buildup of muscle fibers to facilitate the ability of muscle performance in carrying out physical performance (Khlifa, 2010). Jumping and bounding exercises are increasingly being implemented in training regimens to develop leg strength (Reilly, 1991). In addition, training using the plyometric method itself has been widely used in sports that require improving sprint and jumping performance. Football, basketball, handball and rugby are examples of intermittent team sports that combine cyclic and acyclic movements in competitive success (Chelly, 2014).

\subsection{Agility, strength, balance and leg power}

Agility is very dominant in sports whose characteristics require high speed of movement and the ability to change direction suddenly according to the situation at hand and desired (Sheppard and Young, 2007). Strength training really needs to be applied in accordance with Sukadiyanto's explanation (2011: 90) which states that strength must be increased as the underlying foundation in other biomotor components.

According to Lee and Seo (2014) in their research stated that by providing leg muscle strength training in stroke patients with this type of training on walking on a flat surface and therapy on walking stairs resulted in a significant increase in balance ability. Power it can also be formulated in the form of a multiplication between strength and speed, if someone wants to get great power, they must have the ability to issue great power and have the ability to contract quickly (Kawamori, 2004).

Power is one of the major concepts used in study of language. Jones (ps tectalk) argues that power does not exist by itself, it is the people that are responsible for such terms to appear in communication. Ramos (2004) stated that power is important, that it exists every time interaction occurs. Power is the degree to which one interlocutor is able to control the behavior of others (Sterling, 2000). The basis of power relationships are things such as physical strength, wealth, age, sex, also in some institutional role such as in the army, within the family etc. such relation as older than, richer than, stronger than, or any other kind of superiority is all symmetrical relationship. (Bahar et al, 2020)

\section{Research Methods}

This research is a quasi-experimental research type. The research design used in this research is Matching-only design. The sample in this study was taken from the male student population of the 2017 PENJAS PRODI STKIP PGRI Jombang. In taking the sample using a purposive sampling technique, according to Sriundy (2010, p221) the purposive sampling technique requires sampling with certain objectives described in accordance with the research needs. samples are taken that meet the criteria, namely:male student of STKIP PGRI Jombang 
class 2017 STKIP PENJAS class 2017who followed the male gender, healthy students with ideal body mass index. In the Slovin formula the error rate used is $5 \%$ or 0.05 . Slovin's formula, namely:

$\mathrm{n}=\frac{N}{1+N e^{2}}$

With a population of 47 , the result of calculating the sample size using the above formula is that the number of samples is 42 . Because there are 3 groups, each group consists of 14 students. The technique of grouping samples using ordinal pairing technique. The samples were grouped by ordinal pairing. Ordinal pairing is one of the sample grouping events with a ranking system. The purpose of using ordinal pairing is to equalize the ability of the sample in each group.

The agility test uses a side step test tool, namely by doing as many side steps as possible for 20 seconds. Strength test using toolsLeg Dynamometer by bending the knees to form an angle of \pm 1200 and trying as hard as possible to straighten both legs. Test your balance using a balance beam by standing one foot on the plate with your eyes closed and holding on as long as possible. The leg power test uses a force plate by jumping up as hard as you can for 6 seconds.

\section{Results and Discussion}

Table 1. Research Results

\begin{tabular}{|c|c|c|c|c|}
\hline Group & Agility (times) & Strength (kg) & $\begin{array}{c}\text { Balance } \\
\text { (seconds) }\end{array}$ & $\begin{array}{c}\text { Leg Power } \\
\text { (Joule) }\end{array}$ \\
\hline \multicolumn{5}{|c|}{ BEP SL $(n=14)$} \\
\hline Pre & $28.93 \pm 6.04$ & $145.89 \pm 19.41$ & $35,50 \pm 19.83$ & $68.74 \pm 12.58$ \\
\hline Post & $33.93 \pm 5.69$ & $182.43 \pm 24.60$ & $47,50 \pm 21.10$ & $84.86 \pm 9.14$ \\
\hline Sig. & ,000 & 000 &, 000 &, 000 \\
\hline \multicolumn{5}{|c|}{ BEP DL $(n=14)$} \\
\hline Pre & $29.07 \pm 4.29$ & $148.18 \pm 32.02$ & $33.50 \pm 19.72$ & $71.52 \pm 6.85$ \\
\hline Post & $31.43 \pm 4.52$ & $166.71 \pm 31.96$ & $39.57 \pm 20.69$ & $79.98 \pm 8.31$ \\
\hline Sig. & 000 & 000 & 000 & 000 \\
\hline \multicolumn{5}{|c|}{ BEP » Physical Components } \\
\hline Sig. & 000 & 000 & ,000 & ,000 \\
\hline & BEP SL > BEP DL & BEP SL > BEP DL & BEP SL > BEP DL & BEP SL > BE \\
\hline
\end{tabular}

The variables of leg muscle strength, balance, agility, and leg muscle power have an average with a significance result of $<0.05$ with the meaning of rejecting Ho, then there is a significant difference between leg muscle strength, balance, agility, and leg muscle power before doing the exercise and after doing exercises in the single leg (SL) group. In the double leg (DL) group, the variables of leg muscle strength, balance, agility, and leg muscle power have a mean with a significance result of $<0.05$ with the meaning of rejecting Ho, then there is a significant difference between leg muscle strength, balance, agility, and power. leg muscles before and after exercising.

Plyometric training has gained popularity in the world of coaching, both in the field of improving the physical ability of athletes or in order to maintain physical condition. This is because this exercise is easy to learn and optimal results. Plyometric training methods or those that use the principle of eccentric and concentric muscles have an influence in increasing jump results. In this study using the bounding plyometric method with a duration of six weeks. The 
six-week training duration was chosen because it is known that neural and muscular adaptations can occur over this time span (Miller et al., 2006; McClenton, Brown, Coburn, \& Kersey, 2008; Thomas, et al., 2009). In accordance with the research that has been done, the selection of exercises for six weeks can improve the performance of the lower extremities, namely power and leg strength.

Progressive training using one-legged jumping is better for improving speed, balance and explosive power than using two legs. This is relevant to the research conducted by Kusnanik (2015) on one-leg and two-leg exercises showing a more effective increase using one leg, although both have an equally significant increase. Furthermore, the findings of this study are consistent with the results of other relevant studies which found that one-legged jumping exercise can increase jumping height rapidly compared to two-legged; plyometric training with one leg is better than two legs to increase explosive power, therefore it can be used as a reference to increase speed and explosive power (Makaruk, 2011; Dalacore et al, in McCurdy, 2005).

In the literature review that the researcher reads, there is an opinion which states that the ability to balance is more or less influenced by explosive power (Atilgan 2013). Plyometric exercises are widely recognized as a potential tool for improving functional sports performance. During plyometric training, the muscles change rapidly from an eccentric contraction phase to a concentric phase. Decreasing the duration of the amortization phase exploits the stored elastic energy and stretch reflex, allowing a greater than normal release of force during the concentric movement phase. Ramirez-Campillo (2015). It is believed that balance will increase because the leg muscles also experience an increase in strength and explosive power due to double leg bounding training.

Plyometric training is widely used to improve the ability of skeletal muscles to generate power. The double leg bounding method involves a series of repetitive movements, each consisting of a rapid change of body direction, followed immediately by a brief transitional phase and rapid acceleration. This rapid combination of eccentric and concentric muscle activity involves repeated stretch-shortening cycles (SSCs), which provide a physiological advantage because the muscle strength developed during the concentric phase is amplified by the previous eccentric action (Tofas et al., 2008 ; Chatzinikolaou, et al., 2010). The movement that moves places and quickly makes agility biomotor abilities increase. In several literature studies, researchers found that there are two typical models of plyometric exercises that are often carried out by trainers with the aim of increasing certain aspects, these aspects are increasing leg power, using dominant movements such as hopping and increasing the frequency of these movements, To speed up movement in the legs, the movement is done with fast dominant movements (Jovanovic, 2011).

This has something to do with the treatment carried out by researchers, namely plyometric exercises by means of fast bouncing or bounding movements. There is a theoretical basis regarding the concept of ground reaction force and ground contact time which is related to the research conducted by the researcher. The plyometric training model that is mostly done by some people is explosive or fast. Exercises that increase explosive power or power are exercises that have a high ground reaction force model and fast ground contact time. Single leg bounding exercises tend to take the form of hopping movements. The hopping motion in plyometrics according to the data conducted by the researcher resulted in greater ground reaction force and faster ground contact time than exercise using the other leg. On this basis, although there are claims that two-legged exercises are no better than onelegged exercises. However, if the typical movements designed in the exercise program are carried out according to the literature review above, the results will be different. 


\section{Conclusion}

1. There is a significant effect of using Single leg bounding exercise on increasing physical performance abilities of strength, balance, agility and power.

2. There is a significant effect of using Double leg bounding exercise on increasing physical performance ability, balance strength, agility and power.

3. There is a significant difference in the form of Single leg bounding and Double leg bounding exercises to increase strength, balance, agility and power and the most effective form of exercise in increasing the ability of leg muscle strength, balance, agility and power by using single leg bounding exercises.

\section{Recommendations}

1. To keep the intensity of the exercise high, the heart rate is maintained by using a pulse detector or heart rate monitor.

2. Further research is needed physiologically regarding the effect of differences in the bounding method, this is because this method is still common in the selection of other plyometric exercises such as countermovement jumps, depth jumps and others which are still the main choice of trainers and researchers.

3. Single leg bounding and Double leg bounding exercises are able to increase physical performance abilities, balance strength, agility and leg power. So that this method can be used by achievement sports that require biomotor abilities, such as soccer, volleyball, basketball and other sports that require lower extremity biomotor abilities.

\section{References}

Aghababaei Z (2010). A comparative Study Of the Effects Of the Selected Plyometric, Weight resistance and Plyometric weight resistance Training Methods On Leg explosive power, Lower extremity muscular Strength and Agility Of Trained Females. Rasht: Guilan University;(2010).

Atilgan Erkut $O$ (2013). Effects of tramboline training on jump, leg strenght, static and dynamic balance of boys. Science of Gymnastics Journal, 5(2): 15-25.

Bahar, et al. (2020). Teacher's Use of Power Bases as Perceived by ELT Students in Tertiary Education. Budapest International Research and Critics Institute-Journal (BIRCIJournal). P. 1426-1434.

Chamari K, Hachana Y, Ahmed Y, Galy O, Sghaïer F, Chatard J, et al (2004). Field and laboratory testing in young elite soccer players. Br J Sports Med. (2004);38(2):191-6.

Chatzinikolaou, A., Fatouros, I.G., Gourgoulis, V., Avloniti, A., Jamurtas, A.Z., \& Nikolaidis, M.G. (2010). Time course of changes in performance and inflammatory responses after acute plyometric exercise. Journal of Strength and Conditioning Research, 24, 1389-1398.

Chelly MS, Hermassi S, Aouadi R dan Shephard RJ (2014). Effects of 8-week in-season plyometric training on upper and lower limb performance of elite adolescent handball players. J Strength Cond Res, 28: 1401- 1410.

Davies G, Riemann BL, Manske R (2015). Current concepts of plyometric exercises. Int J Sports Phys Ther. 2015;10(6):760-86.

Delcore, G, Mathieu, W, Salazar, W, and Hernandez, J. (1998) Comparison between one-leg and two-leg plyometric training on vertical jump performance [Abstract]. Med Sci Sports Exerc 30 (Suppl.): 615, 1998

Jovanovic Mario. (2011). Effects Of Speed,Agility,Quickness Training Method On Power Performance In Elite Soccer Players. Journal Of Strength And Conditioning Research 
Kawamori N, and Haff GG. (2004). The Optimal Training Load For The Development of Muccular Power. Journal of Strength and Conditioning Research (18):675-684.

Khlifa R., Aouadi R., Hermassi S., Chelly MS., Jlid MC., Hbacha H., et al (2010). Effects of a plyometric training program with and without added load on jumping ability in basketball players. J Strength Cond Res.: 24:2955-61.

Kusnanik, N. W. (2015) The Effect of Single Leg Hop Progression and Double Legs Hop Progression Exercise to Increase Speed and Explosive Power of Leg Muscle. Sport Mont Journal

Lee J. H and Seo K. C., (2014). "The Effects of Stair Walking Training on the Balance Ability of Chronic Stroke Patients".Republik of Korea. J. Phys. Ther. Sci. Vol. 26, No. 4: $517-$ 520.

Makaruk, Hubert et all (2011) Effects Of Unilateral And Bilateral Plyometric Training On Power And Jumping Ability In Women. Journal of Strength and Conditioning Research 2011 National Strength and Conditioning Association

McClenton, L., Brown, L.E., Coburn, J.W., \& Kersey, R.D. (2008). The effect of short-term vertimax vs. depth jump training on vertical jump performance. Journal of Strength and Condition 459-465.

Ramirez-Campillo R1., Burgos C., Henríquez-Olguín C., Andrade DC., Martínez C., Alvarez C., CastroSepúlveda M., Marques MC., Izquierdo M., (2015). Effect of unilateral, bilateral and combined plyometric training on explosive and endurance performance of young soccer players. J Strength Cond Res, 29(5): 1317-28

Reilly T.,et all., (1991). Changes in stature during exercise and sports training. Department of Orthopaedic and Accident Surgery, Royal Liverpool Hospital, Prescott Street, Liverpool, U K

S. Van de Hoef., B. M. A., Huisstede., M. S., Brink., N. de Vries., E. A., Goedhart., F. J. G., Backx., (2017). The preventive effect of the bounding exercise programme on hamstring injuries in amateur soccer players: the design of a randomized controlled trial. Department of Rehabilitation, Physical Therapy Science and Sports, Rudolf Magnus Institute of Neurosciences, University Medical Center Utrecht, Utrecht, The Netherlands

Sheppard J., M and Young W.B., (2007). "Agility literature review: Classifications, Training and Testing".Journal of Sports Sciences, September, 24(9): 919- 932.

Slimani M., dkk., (2016). Effects of Plyometric Training on Physical Fitness in Team Sport Athletes: A Systematic Review. Journal of Human Kinetics volume 53, 231-247 DOI: $10.1515 /$ hukin

Sriundy M., I Made. (2010). Pengantar Evaluasi Pengajaran. Surabaya : Unesa University Press

Sukadiyanto., (2011). Pengantar Teori dan Metodologi Melatih Fisik. Bandung: CV. LUBUK AGUNG

Thomas, K., French, D., \& Philip, P.R. (2009). The effect of two plyometric training techniques on muscular power and agility in youth soccer players. Journal of Strength and Conditioning Research, 23, 332-335.

Tofas, T., Jumurtas, A.Z., Fatouros, I., Nikolaidis, M.G., Koutedakis, Y., Sinouris, E.A., Papageorgakopoulou, N., \& Theochathios D.A. (2008). Plyometric exercise increases serum indices of muscle damage and collagen breakdown. Journal of Strength and Conditioning Research, 22, 490-496.

McCurdy, KW, Langford, GA, Doscher, MW, Wiley, LP, and Mallard, KG.(2005) The effects of short-term unilateral and bilateral lowerbody resistance training on measures of strength and power. J Strength Cond Res 19: 9-15, 2005.

Miller, M.G., Herniman, T.J., Ricard, M.D., Cheatham, C.C., \& Michael, T.J. (2006). The effects of a 6-week plyometric training program on agility. Journal of Sport Science and Medicine, 5. 